\title{
The prognostic value of negative lymph node count for patients with gastric cancer who received preoperative radiotherapy
}

\author{
Xinxing Li ${ }^{1, *}$, Weigang Zhang ${ }^{1, *}$, Xianwen Zhang ${ }^{1, *}$, Haolu Wang ${ }^{2}$, Kai Xu ${ }^{1}$, Houshan \\ $\mathrm{Yao}^{1}$, Jun $\mathrm{YaO}^{1}$, Xiaowen Liang ${ }^{2}$ and Zhiqian $\mathrm{Hu}^{1}$ \\ ${ }^{1}$ Department of General Surgery, Changzheng Hospital, The Second Military Medical University, Shanghai 200003, China \\ ${ }^{2}$ Therapeutics Research Centre, School of Medicine, The University of Queensland, Princess Alexandra Hospital, Woolloongabba, \\ QLD 4102, Australia \\ *These authors have contributed equally to this work \\ Correspondence to: Xiaowen Liang, email: x.liang@uq.edu.au \\ Zhiqian Hu, email: huzhiq163@163.com \\ Keywords: gastric cancer, preoperative radiotherapy, negative lymph node, survival \\ Received: October 29, $2016 \quad$ Accepted: December 27, 2016 Published: February 01, 2017 \\ Copyright: Li et al. This is an open-access article distributed under the terms of the Creative Commons Attribution License 3.0 (CC \\ BY 3.0), which permits unrestricted use, distribution, and reproduction in any medium, provided the original author and source are \\ credited.
}

\section{ABSTRACT}

Negative lymph node (NLN) count provides accurate prognostic information in patients with gastric cancer. However, it is unclear whether NLN still has prognostic value for patients received preoperative radiotherapy. In this study, Surveillance, Epidemiology, and End Results Program (SEER)-registered gastric cancer patients were used for analysis. Clinicopathological characteristics and survival time were collected. Univariate and multivariate Cox proportional hazards models were used to assess the risk factors for survival. NLN count was validated as an independent prognostic factor in both univariate and mulivariate analysis $(P<0.001)$. X-tile plots identified 12 as the optimal cutoff value to divide the patients into high and low risk subsets in terms of survival rate. Nomogram based on cancer-specific survival was successfully established according to all significant factors. The C-index was $\mathbf{0 . 6 3 0}$ (95\% CI: 0.605-0.655). Subgroup analysis showed that NLN count was a prognosis factor for patients with advanced gastric cancer (stage ypII and ypIII). In conclusion, our results firmly demonstrated that NLN count was an independent prognostic factor for patients with gastric cancer who received preoperative radiotherapy. It provides more accurate prognostic information especially for patients with advanced gastric cancer (stage ypII and ypIII). Nomograms based on cancer-specific survival could be recommended as practical models to evaluate prognosis.

\section{INTRODUCTION}

Gastric cancer (GC) is the fourth most common malignancy and the second leading cause of cancer related death worldwide [1]. Surgical resection is the only curative option, but outcomes are poor [2]. Preoperative radiotherapy (Pre-RT) offers multiple advantages. Trials from Europe and Asia have been conducted to determine the feasibility of Pre-RT for GC [3]. Several randomized studies and meta-analysis have demonstrated a survival benefit for Pre-RT in patients with GC compared with surgery alone [3-5].
Lymph node (LN) metastases indicate worse treatment response and poorer survival. The American Joint Committee on Cancer (AJCC) successively established standards for LN stage based on metastatic LNs in the anatomical positions and the number of LN metastasis [2]. While the node-positive patients with GC are heterogeneous and the prognosis of these patients cannot be stratified by the node-stage only $[6,7]$. Therefore, the concept of negative lymph node (NLN) counts attracted attention recently. It can serve as a prognostic indicator in various cancers, such as cervical [8], breast [9], esophagus [10] and GC [11]. However, Pre-RT can yield tumor downstaging, 
reduce the burden of residual microscopic disease at surgery and reduce the number of LNs retrieved in operation [3]. With the decreased LNs retrieval, the prognostic value of the LN count might also diminish [12]. Thus, it is unclear whether NLN still has prognostic value for survival of patients with GC who received Pre-RT. The purpose of this study was to assess the association between NLN count and survival of patients with GC who received Pre-RT. In order to get convincing results in a larger series of patients, we used the SEER (Surveillance, Epidemiology and End Results)-registered database to analyze this association, and determine the optimal cutoff value of NLN count.

\section{RESULTS}

\section{Patient characteristics in SEER database}

In our study period from 2004 to 2013, a total of 1,346 patients with GC who received Pre-RT met our selection criteria, including 1,130 male and 216 female. The median age of patients was 62 years $(20$ - 93). There were 738 patients with stage ypN0, 297 with stage ypN1, 214 with stage ypN2 and 97 with stage ypN3. The demographics and pathological features of patients are summarized in Table 1 . The ypN stage was closely correlated with sex, year of diagnosis, grade, histologic type, and ypT stage $(\mathrm{P}<0.05)$.

\section{The optimal cutoff value for NLNs determined by $\mathrm{X}$-tile program}

To assess the influence of different NLN count on cancer-specific survival (CSS), we analyzed the individual result using different NLN count ranging from 1 to 24. The 3-year and 5-year CSSs were calculated for patients with $\mathrm{N}$ (NLNs number) or more nodes and less than $\mathrm{N}$ nodes. As shown in Table 2 , NLN count was a prognosis factor for number ranging from 1 to 18 . The 5 -year CSS rate increased from $14.5 \%$ to $46.5 \%$. Next $\mathrm{X}$-tile plots were constructed and the maximum $\chi 2$ logrank value of 26.872 was produced (Figure 1, $\mathrm{P}<0.001$ ), applying 12 as the optimal cutoff value to divide the cohort into high and low risk subsets in terms of CSS. There was a significant difference in 3-year and 5-year CSS between two subsets $(42.3 \%$ v.s. $56.2 \%$, and $30.5 \%$ v.s. $40.8 \%$, respectively).

\section{Nomograms for predicting survival of patients with GC who received Pre-RT}

According to univariate analysis, NLN count $(\mathrm{P}<0.001)$, sex $(\mathrm{P}=0.018)$, year of diagnosis $(\mathrm{P}=0.045)$, grade $(\mathrm{P}=0.012)$, histologic type $(\mathrm{P}<0.001)$ and ypN stage $(\mathrm{P}<0.001)$ were associated with poor survival. In multivariate Cox analysis (Table 3 ), grade, ypN stage and NLN counts were independently prognostic factors. A higher number of NLN counts showed a favorable effect on survival $(\mathrm{HR}=1.375,95 \% \mathrm{CI}: 1.166-1.621, \mathrm{P}<$ $0.001)$.

In order to predict CSS, the nomogram was established by multivariate Cox regression model according to all significantly independent factors including grade, ypN stage and NLN counts (Figure 2). Nomogram could be interpreted by summing up the points assigned to each variable, which was indicated at the top of scale. The total points could be converted to predicted 3-year and 5-year CSS to obtain the probability of death. The Harrell's C-index for CSS prediction was 0.630 (95\% CI: 0.605-0.655). Calibration curves for the nomogram revealed no deviations from the reference line and no need of recalibration (Figure 2).

\section{Subgroup analysis for evaluating the effect of NLN count according to TNM stage}

According to the AJCC-7 GC staging system, patients with LNs metastases were divided into three subgroups including stage ypI, ypII and ypIII. We then further analyzed the effects of NLN on survival in each subgroup. As shown in Table 4 , NLN count was an independently prognostic factor in the stage ypII $\left(\chi^{2}=\right.$ $8.300, \mathrm{P}=0.004)$ and stage ypIII subgroups $(\chi 2=13.404$, $\mathrm{P}<0.001)$, but not in the stage ypI subgroup $(\chi 2=1.904$, $\mathrm{P}=0.168)$ on both univariate and multivariate analysis (Figure 3, $\mathrm{P}<0.001$ ).

\section{DISCUSSION}

Despite a decreasing incidence of GC in some developed countries over the past decade, about 1,000, 000 new cases are diagnosed each year globally, with the 5-year survival less than $30 \%$ [13]. LN metastasis is considered one of the most significant prognostic factors [14]. Yet, the number of positive LN is often affected by many facts such as neoadjuvant therapy, and the number of LN retrieved and inspected [3, 15]. Once the LN retrieved is not enough, the prediction of survival would be inaccurate. The intended purpose of Pre-RT is tumor down-staging by decreasing the primary tumor bulk and reducing the burden of residual associated LN metastases at surger [3]. It has been reported that Pre-RT may cause radiation-induced lymphocyte destruction and stromal fibrosis resulting in alterations of the morphology of the LNs, making LN detection during operation more difficult [3]. Some researchers also found that a decreased LN count after Pre-RT was related to good survival [4, 5].

NLN count has a unique advantage that it is little influenced by the number of LN retrieved [11]. The more NLN count is, the better the survival would be. It has been reported that the NLN count was a key factor for the survival of patients with GC after curative resection [16]. In this study, we found that the NLN count was an independent prognosis factor for patients with GC who received Pre-RT. And we also identified the optimal cutoff value for NLN count as 12 . Obviously, NLN 
Table 1: Demographics and pathological features of patients with GC who received Pre-RT

\begin{tabular}{|c|c|c|c|c|c|c|c|}
\hline \multirow{2}{*}{ Variable } & \multirow{2}{*}{ N (1346) } & ypNo & ypN1 & ypN2 & ypN3 & \multirow{2}{*}{$\chi^{2}$} & \multirow{2}{*}{ P value } \\
\hline & & N $(\%)$ & N $(\%)$ & N (\%) & N $(\%)$ & & \\
\hline \multicolumn{8}{|l|}{ Sex } \\
\hline Male & 1130 & $595(52.7)$ & $267(23.6)$ & $189(16.7)$ & $79(7.0)$ & 17.347 & 0.001 \\
\hline Female & 216 & $143(66.2)$ & $30(13.9)$ & $25(11.6)$ & $18(8.3)$ & & \\
\hline \multicolumn{8}{|l|}{ Age } \\
\hline$<60$ & 526 & $267(50.8)$ & $121(23.0)$ & $93(17.7)$ & $45(8.6)$ & 6.854 & 0.077 \\
\hline$\geq 60$ & 820 & $471(57.4)$ & $176(21.5)$ & $121(14.8)$ & $52(6.3)$ & & \\
\hline \multicolumn{8}{|l|}{ Year of diagnosis } \\
\hline 2004-2008 & 495 & $259(52.3)$ & $114(23.0)$ & $73(14.7)$ & $49(9.9)$ & 9.756 & 0.021 \\
\hline $2009-2013$ & 851 & $479(56.3)$ & $183(21.5)$ & $141(16.6)$ & $48(5.6)$ & & \\
\hline \multicolumn{8}{|l|}{ Race } \\
\hline White & 1202 & $662(55.1)$ & $267(22.2)$ & $186(15.5)$ & $87(7.2)$ & 3.846 & 0.698 \\
\hline Black & 59 & $29(49.2)$ & $11(18.6)$ & $13(22.0)$ & $6(10.2)$ & & \\
\hline Others & 85 & $47(55.3)$ & $19(22.4)$ & $15(17.6)$ & $4(4.7)$ & & \\
\hline \multicolumn{8}{|l|}{ Grade } \\
\hline $\begin{array}{l}\text { Well-moderately } \\
\text { differentiated }\end{array}$ & 487 & $311(63.9)$ & $110(22.6)$ & $52(10.7)$ & 14 (28.7) & 71.162 & $<0.001$ \\
\hline $\begin{array}{l}\text { Poor- } \\
\text { undifferentiated }\end{array}$ & 728 & $337(46.3)$ & $165(22.7)$ & $153(21.0)$ & $73(10.1)$ & & \\
\hline Unkown & 131 & $90(68.7)$ & $22(16.8)$ & $9(6.9)$ & $10(7.6)$ & & \\
\hline \multicolumn{8}{|l|}{ Histologic type } \\
\hline Adenocarcinoma & 1113 & $626(56.2)$ & $245(22.0)$ & $175(15.7)$ & $67(6.0)$ & 23.931 & 0.001 \\
\hline $\begin{array}{l}\text { Signet ring cell } \\
\text { carcinoma }\end{array}$ & 159 & $70(44.0)$ & $33(20.8)$ & $33(20.8)$ & $23(14.5)$ & & \\
\hline Others & 74 & $42(56.8)$ & $19(25.7)$ & $6(8.1)$ & $7(9.5)$ & & \\
\hline \multicolumn{8}{|l|}{ ypT Stage } \\
\hline $\mathrm{T} 1$ & 136 & $102(75.0)$ & $20(14.7)$ & $12(8.8)$ & $2(1.5)$ & 44.418 & $<0.001$ \\
\hline $\mathrm{T} 2$ & 182 & $110(60.4)$ & $46(25.3)$ & $17(9.3)$ & $9(4.9)$ & & \\
\hline $\mathrm{T} 3$ & 576 & $309(53.6)$ & $121(21.0)$ & $95(16.5)$ & $51(8.9)$ & & \\
\hline $\mathrm{T} 4$ & 452 & $217(48.0)$ & $110(24.3)$ & $90(19.9)$ & $35(7.7)$ & & \\
\hline
\end{tabular}

count is a good supplement for LN stage and TNM stage on evaluating prognosis, especially for patients with advanced GC (stage ypII and ypIII) who received Pre-RT. Until now, there has been no report confirming the mechanism of NLNs influencing on the prognosis of
GC. It is suggested that lymphatic micrometastasis is a key etiology of recurrence and metastasis after resection of GC [17]. LN micrometastasis, is common in nodes with the size ranging from $0.2 \mathrm{~mm}$ to $2.0 \mathrm{~mm}$ which determined to be negative by HE staining, but positive 
Table 2: Univariate analysis of the influence of different NLN count on CSS in patients with GC who received Pre-RT

\begin{tabular}{|c|c|c|c|c|c|c|c|c|c|c|c|}
\hline $\begin{array}{l}\text { Total } \\
\text { NLNs } \\
\end{array}$ & No. & $\begin{array}{c}\text { 3-year } \\
\text { CCS }\end{array}$ & $\begin{array}{c}5 \text {-year } \\
\text { CCS }\end{array}$ & $\begin{array}{c}\text { Log rank } \\
\chi^{2} \text { test }\end{array}$ & P value & $\begin{array}{r}\text { Total } \\
\text { NLNs } \\
\end{array}$ & No. & $\begin{array}{c}\text { 3-year } \\
\text { CCS }\end{array}$ & $\begin{array}{c}5 \text {-year } \\
\text { CCS }\end{array}$ & $\begin{array}{c}\text { Log rank } \\
\chi 2 \text { test }\end{array}$ & P value \\
\hline$<1$ & 27 & $27.2 \%$ & $14.5 \%$ & 12.171 & $<0.001$ & $<13$ & 738 & $42.3 \%$ & $30.5 \%$ & 27.123 & $<0.001$ \\
\hline$\geq 1$ & 1319 & $48.8 \%$ & $38.3 \%$ & & & $\geq 13$ & 608 & $56.2 \%$ & $48.1 \%$ & & \\
\hline$<2$ & 69 & $24.6 \%$ & $17.4 \%$ & 22.697 & $<0.001$ & $<14$ & 798 & $43.1 \%$ & $31.8 \%$ & 21.641 & $<0.001$ \\
\hline$\geq 2$ & 1277 & $49.7 \%$ & $39.0 \%$ & & & $\geq 14$ & 548 & $56.7 \%$ & $48.0 \%$ & & \\
\hline$<3$ & 109 & $27.5 \%$ & $17.9 \%$ & 29.529 & $<0.001$ & $<15$ & 844 & $43.4 \%$ & $32.5 \%$ & 21.094 & $<0.001$ \\
\hline$\geq 3$ & 1237 & $50.3 \%$ & $39.7 \%$ & & & $\geq 15$ & 502 & $57.6 \%$ & $48.2 \%$ & & \\
\hline$<4$ & 167 & $32.3 \%$ & $24.5 \%$ & 23.963 & $<0.001$ & $<16$ & 888 & $43.6 \%$ & $32.5 \%$ & 23.181 & $<0.001$ \\
\hline$\geq 4$ & 1179 & $50.8 \%$ & $39.9 \%$ & & & $\geq 16$ & 458 & $58.5 \%$ & $50.0 \%$ & & \\
\hline$<5$ & 223 & $37.0 \%$ & $27.4 \%$ & 18.418 & $<0.001$ & $<17$ & 938 & $44.5 \%$ & $33.6 \%$ & 16.224 & $<0.001$ \\
\hline$\geq 5$ & 1123 & $50.7 \%$ & $40.0 \%$ & & & $\geq 17$ & 408 & $58.5 \%$ & $49.4 \%$ & & \\
\hline$<6$ & 275 & $39.0 \%$ & $29.3 \%$ & 16.654 & $<0.001$ & $<18$ & 981 & $45.7 \%$ & $35.1 \%$ & 7.492 & 0.006 \\
\hline$\geq 6$ & 1071 & $50.9 \%$ & $40.2 \%$ & & & $\geq 18$ & 365 & $56.8 \%$ & $46.5 \%$ & & \\
\hline$<7$ & 356 & $39.5 \%$ & $29.5 \%$ & 19.387 & $<0.001$ & $<19$ & 1027 & $46.6 \%$ & $36.1 \%$ & 3.552 & 0.059 \\
\hline$\geq 7$ & 990 & $51.7 \%$ & $41.0 \%$ & & & $\geq 19$ & 319 & $55.2 \%$ & $44.4 \%$ & & \\
\hline$<8$ & 426 & $39.9 \%$ & $29.8 \%$ & 20.603 & $<0.001$ & $<20$ & 1061 & $47.0 \%$ & $36.2 \%$ & 3.248 & 0.071 \\
\hline$\geq 8$ & 920 & $52.5 \%$ & $41 . .9 \%$ & & & $\geq 20$ & 285 & $54.3 \%$ & $45.4 \%$ & & \\
\hline$<9$ & 483 & $40.0 \%$ & $28.3 \%$ & 26.671 & $<0.001$ & $<21$ & 1094 & $47.2 \%$ & $36.5 \%$ & 2.188 & 0.139 \\
\hline$\geq 9$ & 863 & $53.3 \%$ & $44,1 \%$ & & & $\geq 21$ & 252 & $54.7 \%$ & $45.2 \%$ & & \\
\hline$<10$ & 554 & $41.2 \%$ & $29.0 \%$ & 25.278 & $<0.001$ & $<22$ & 1130 & $47.4 \%$ & $36.5 \%$ & 2.868 & 0.090 \\
\hline$\geq 10$ & 792 & $53.6 \%$ & $45.0 \%$ & & & $\geq 22$ & 216 & $54.7 \%$ & $46.9 \%$ & & \\
\hline$<11$ & 611 & $41.7 \%$ & $30.0 \%$ & 24.380 & $<0.001$ & $<23$ & 1152 & $47.6 \%$ & $36.9 \%$ & 1.473 & 0.225 \\
\hline$\geq 11$ & 735 & $54.2 \%$ & $45.4 \%$ & & & $\geq 23$ & 194 & $53.6 \%$ & $44.9 \%$ & & \\
\hline$<12$ & 663 & $42.6^{\wedge}$ & $31.0 \%$ & 21.310 & $<0.001$ & $<24$ & 1162 & $47.7 \%$ & $37.0 \%$ & 1.189 & 0.276 \\
\hline$\geq 12$ & 683 & $54.3 \%$ & $45.4 \%$ & & & $\geq 24$ & 184 & $53.2 \%$ & $43.9 \%$ & & \\
\hline
\end{tabular}
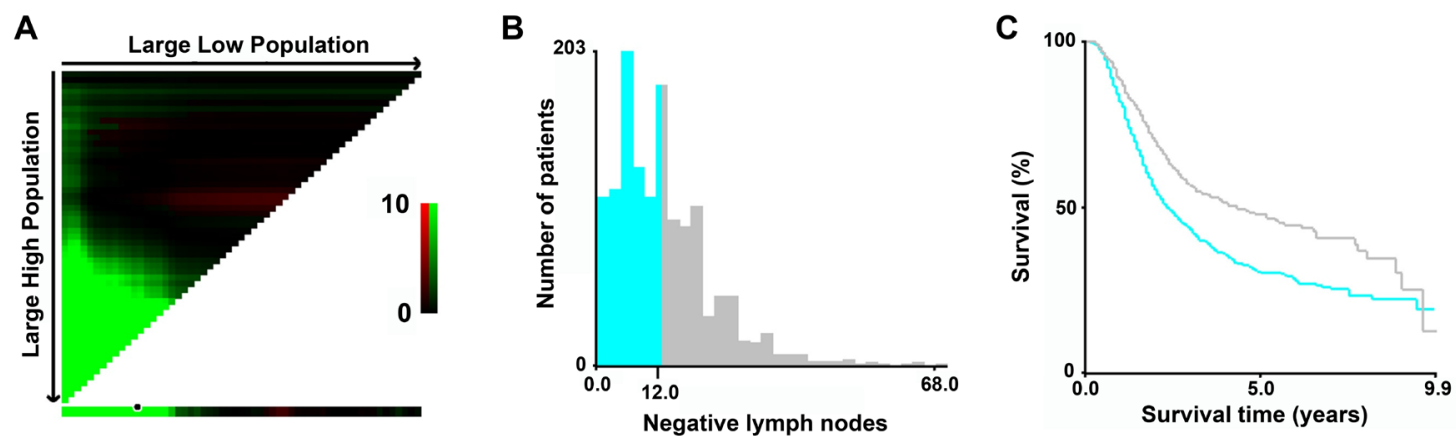

Figure 1: X-tile analysis of survival data from the SEER registry. X-tile analysis was performed using patients' data from the SEER registry, equally divided into training and validation sets. X-tile plots of the training sets are shown with plots of matched validation sets shown in the smaller inset A. The optimal cut-point highlighted by the black circle in the left panels is shown on a histogram of the entire cohort B., and a Kaplan-Meier plot C. P values were determined using the cutoff point defined in the training set and applying it to the validation set. (The optimal cutoff value for NLN count is $12, \chi^{2}=26.872, \mathrm{P}<0.001$.) 
Table 3: Univariate and multivariate survival analysis for evaluating the influence of NLNs on CSS

\begin{tabular}{|c|c|c|c|c|c|c|}
\hline \multirow{2}{*}{ Variable } & \multirow{2}{*}{$\begin{array}{c}\text { 3-year } \\
\text { CCS }\end{array}$} & \multirow{2}{*}{ 5-year CCS } & \multicolumn{2}{|c|}{ Univariate analysis } & \multicolumn{2}{|c|}{ Multivariate analysis } \\
\hline & & & Log rank $\chi^{2}$ test & P value & HR (95\%CI) & P value \\
\hline Sex & & & 5.596 & 0.018 & & 0.069 \\
\hline Male & $47.0 \%$ & $36.3 \%$ & & & Ref. & \\
\hline Female & $55.3 \%$ & $45.5 \%$ & & & $1.253(0.998 \sim 1.575)$ & \\
\hline Age & & & 0.728 & 0.394 & & NI \\
\hline$<60$ & $49.9 \%$ & $38.9 \%$ & & & & \\
\hline$\geq 60$ & $47.3 \%$ & $37.1 \%$ & & & & \\
\hline Year of diagnosis & & & 4.0 & 0.045 & & 0.389 \\
\hline $2004-2008$ & $45.9 \%$ & $34.9 \%$ & & & Ref. & \\
\hline $2009-2013$ & $50.5 \%$ & $39.6 \%$ & & & $1.702(0.908 \sim 1.264)$ & \\
\hline Race & & & 2.461 & 0.292 & & NI \\
\hline White & $47.7 \%$ & $37.4 \%$ & & & & \\
\hline Black & $49.1 \%$ & $36.2 \%$ & & & & \\
\hline Others & $59.0 \%$ & $45.9 \%$ & & & & \\
\hline Grade & & & 20.972 & $<0.001$ & & 0.012 \\
\hline $\begin{array}{l}\text { Well-moderately } \\
\text { differentiated }\end{array}$ & $55.7 \%$ & $43.8 \%$ & & & Ref. & \\
\hline $\begin{array}{l}\text { Poor- } \\
\text { undifferentiated }\end{array}$ & $43.9 \%$ & $31.6 \%$ & & & $0.886(0.635-0.981)$ & \\
\hline Unkown & $41.0 \%$ & $31.1 \%$ & & & $1.233(0.938-1.465)$ & \\
\hline Histologic type & & & 16.316 & $<0.001$ & & 0.091 \\
\hline Adenocarcinoma & $50.8 \%$ & $40.8 \%$ & & & Ref. & \\
\hline $\begin{array}{l}\text { Signet ring cell } \\
\text { carcinoma }\end{array}$ & $34.0 \%$ & $21.6 \%$ & & & $1.003(0.721 \sim 1.395)$ & \\
\hline Others & $44.4 \%$ & $30.4 \%$ & & & $1.298(0.896 \sim 1.878)$ & \\
\hline ypT Stage & & & 3.338 & 0.342 & & NI \\
\hline $\mathrm{T} 1$ & $50.4 \%$ & $44.8 \%$ & & & & \\
\hline $\mathrm{T} 2$ & $52.1 \%$ & $35.4 \%$ & & & & \\
\hline $\mathrm{T} 3$ & $49.8 \%$ & $37.5 \%$ & & & & \\
\hline $\mathrm{T} 4$ & $44.5 \%$ & $36.7 \%$ & & & & \\
\hline ypN Stage & & & 113.780 & $<0.001$ & & $<0.001$ \\
\hline ypN0 & $61.3 \%$ & $49.2 \%$ & & & Ref. & \\
\hline ypN1 & $37.3 \%$ & $28.8 \%$ & & & $0.366(0.280 \sim 0.480)$ & \\
\hline ypN2 & $30.3 \%$ & $22.4 \%$ & & & $0.625(0.470 \sim 0.833)$ & \\
\hline ypN3 & $20.5 \%$ & $10.5 \%$ & & & $0.714(0.529 \sim 0.963)$ & \\
\hline No. of NLNs & & & 27.123 & $<0.001$ & & $<0.001$ \\
\hline$<13$ & $42.3 \%$ & $30.5 \%$ & & & Ref. & \\
\hline$\geq 13$ & $56.2 \%$ & $48.1 \%$ & & & $1.375(1.166 \sim 1.621)$ & \\
\hline
\end{tabular}


for cytokeratin by immunohistochemicalstaining [18]. It is difficult to find lymphatic micrometastasis during operation. Because the NLN count has potential to reflect the dissection of lymphatic micrometastasis, we can retrieve more NLNs to reduce the residual micrometastases, in order to improve the prognosis of GC. In this study, subgroup analysis showed that NLN count was an independent prognosis factor for $\mathrm{GC}$ patients with stage ypII and ypIII, but not for patients with stage ypI. One possible explanation might be that less $\mathrm{LN}$ is retrieved in GC patients with stage ypI, thus the prediction of survival would be less accurate.

The results of this study have several potential limitations. First, the SEER database does not include information of therapeutic options such as radical resection or palliative therapy, detailed information of chemotherapy, recurrence and metastasis, which may also impact patients' prognosis [11]. Especially the

A

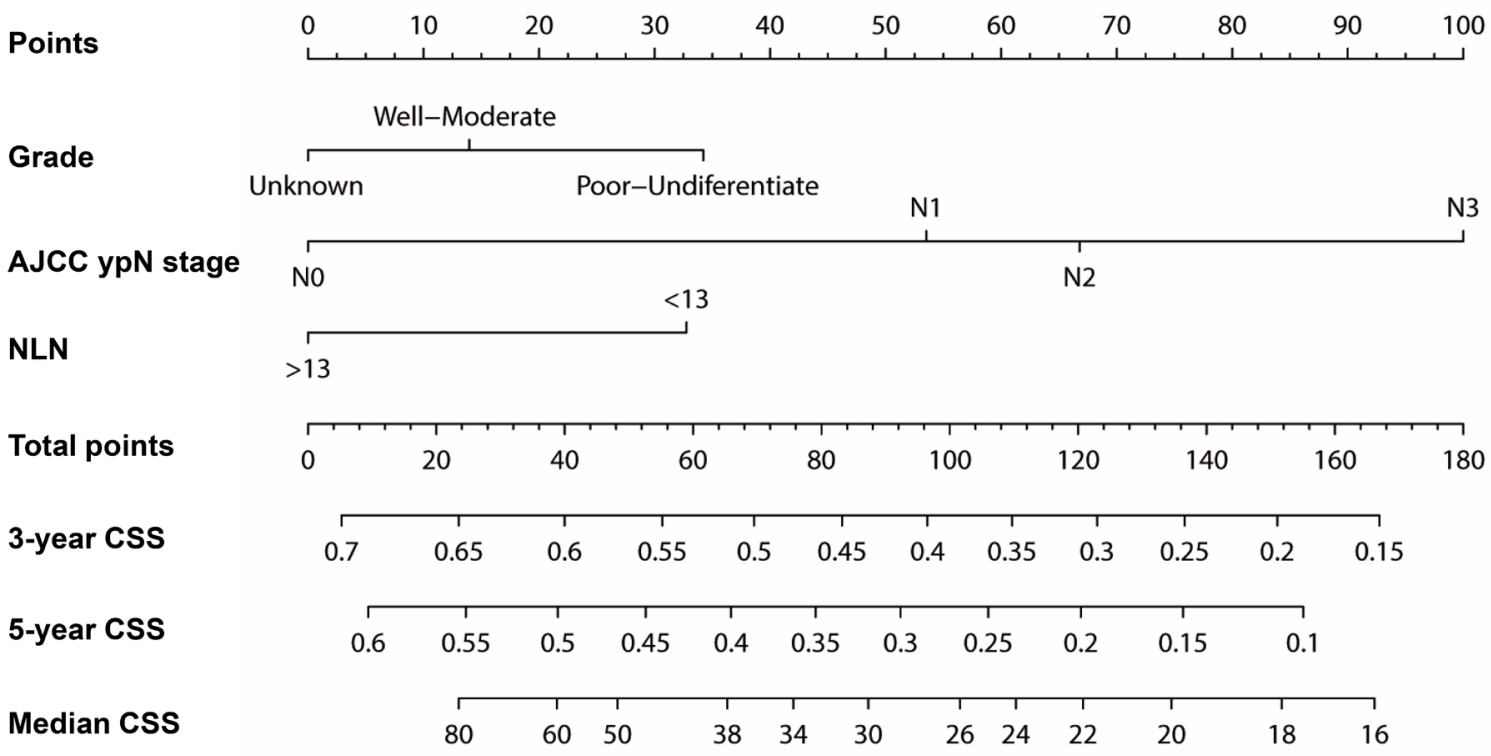

B

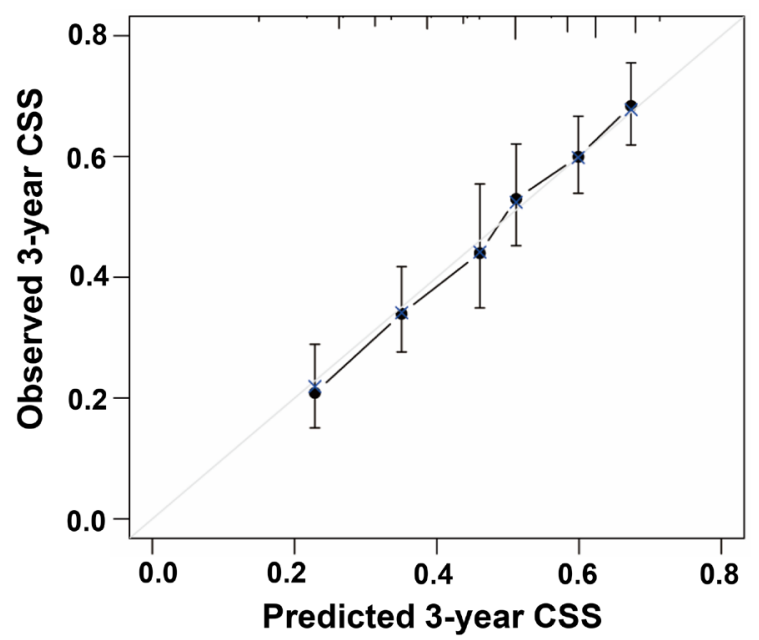

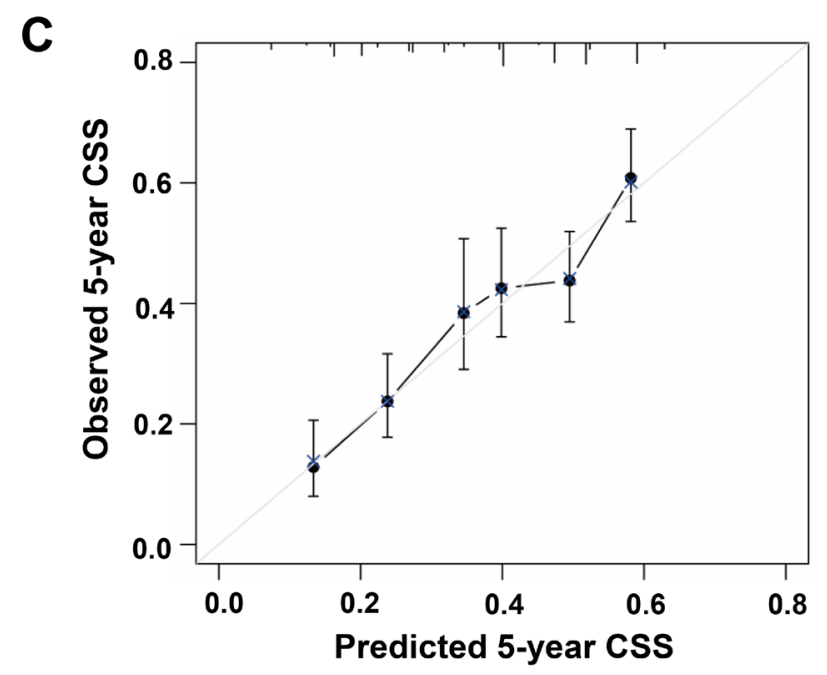

Figure 2: Nomogram for predicting 3-year and 5-year CSS of patients with GC who received Pre-RT. A. Nomograms with clinicopathological characteristics and NLN count. Nomograms could be interpreted by summing up the points assigned to each variable, which was indicated at the top of scale. The total points could be converted to predicted 3-year and 5-year probability of death for patients with GC who received Pre-RT in the lowest scale. The Harrell's C-index for CSS prediction was 0.630 (95\% CI: 0.605-0.655). B and C. Calibration curves using nomograms with clinicopathological characteristics and NLNs for predicting 3-year and 5-year CSS. The X-axis was nomogram-predicted CSS and Y-axis was observed CSS. The reference line was $45^{\circ}$ and indicated perfect calibration. 
Table 4: Univariate and multivariate survival analysis for evaluating the influence of the NLN count on CSS in three subgroups

\begin{tabular}{|c|c|c|c|c|c|c|}
\hline \multirow{2}{*}{ Variable } & \multirow{2}{*}{ 3-year CCS } & \multirow{2}{*}{ 5-year CCS } & \multicolumn{2}{|c|}{ Univariate analysis } & \multicolumn{2}{|c|}{ Multivariate analysis } \\
\hline & & & Log rank $\chi^{2}$ test & $\mathbf{P}$ & HR(95\%CI) & $\mathbf{P}$ \\
\hline \multicolumn{7}{|l|}{ Stage ypI } \\
\hline No. of NLNs & & & 1.904 & 0.168 & NI & \\
\hline$<13$ & $56.3 \%$ & $45.5 \%$ & & & & \\
\hline$\geq 13$ & $65.0 \%$ & $55.5 \%$ & & & & \\
\hline \multicolumn{7}{|l|}{ Stage ypII } \\
\hline No. of NLNs & & & 8.300 & 0.004 & & 0.019 \\
\hline$<13$ & $48.3 \%$ & $33.0 \%$ & & & Reference & \\
\hline$\geq 13$ & $60.3 \%$ & $52.0 \%$ & & & $\begin{array}{c}1.316 \\
(1.045 \sim 1.656)\end{array}$ & \\
\hline \multicolumn{7}{|l|}{ Stage ypIII } \\
\hline No. of NLNs & & & 13.404 & $<0.001$ & & 0.001 \\
\hline$<13$ & $27.7 \%$ & $20.0 \%$ & & & Reference & \\
\hline$\geq 13$ & $38.9 \%$ & $32.8 \%$ & & & $\begin{array}{c}1.641 \\
(1.238 \sim 2.176)\end{array}$ & \\
\hline
\end{tabular}

preoperative chemotherapy has already been recognized as effective for latent lymph node micrometastasis [19]. It actually may have great impact on the prognosis and NLN count [20]. Thus, additional trials will be needed to investigate whether NLN still has prognostic value count on survival of patients with GC who received chemotherapy. Second, different operative approaches, doctors and even pathologist would affect the detective rate of total LN and metastatic LN, but the SEER do not include these information [12]. Third, preoperative clinical grading and the information about tumor and $\mathrm{LN}$ recession response to treatment are still uncertain. All of these factors may influence the curative effect of neoadjuvant therapy and the survival.

In conclusion, our analysis of the SEER database revealed that NLN count (with an optimal cutoff value of 12) in was an independent prognosis factor for patients with GC who received Pre-RT. Subgroup analysis showed that NLN count provided more accurate prognostic information especially for patients with advanced GC (stage ypII and ypIII). Nomograms based on CSS could be recommended as practical models to evaluate prognosis.
A

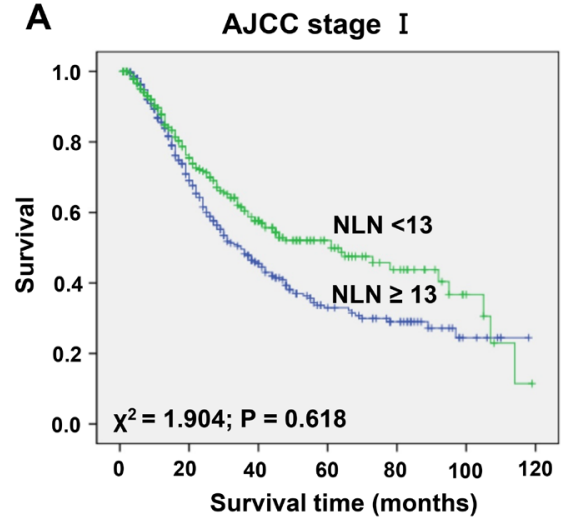

B

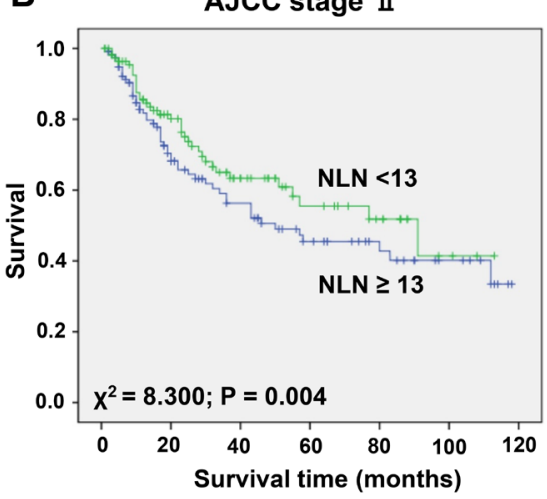

C AJCC stage III

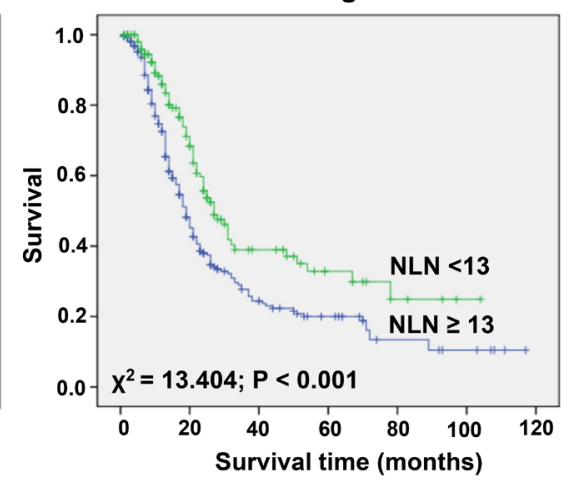

Figure 3: Log-rank tests of CSS comparing patients with NLNs $(<13 \mathrm{VS} \geq 13)$ for A. stage ypI: $\chi 2=1$. 904, P = 0.618; B. stage ypII: $\chi^{2}$ $=8.300, \mathrm{P}=0.004$; and $\mathbf{C}$. stage ypIII: $\chi^{2}=13.404, \mathrm{P}<0.001$. 


\section{MATERIALS AND METHODS}

\section{Patient selection}

All data was obtained from the SEER database. The current SEER database consists of 18 population-based cancer registries that represent approximately $26 \%$ of the population in the United States. The SEER data contain no identifiers and are publicly available for studies of cancerbased epidemiology and health policy.

The National Cancer Institute's SEER*Stat software (Surveillance Research Program, National Cancer Institute SEER*Stat software, www.seer.cancer.gov/seerstat (Version 8.3.2), was used to identify patients whose pathological diagnosis as GC between 2004 and 2013. Only patients who underwent preoperative radiotherapy and surgical treatment with age of diagnosis more than 18 years were included. Histological type were limited to adenocarcinoma $(8140 / 3,8144 / 3,8255 / 3,8211 / 3$, $8260 / 3,8263 / 3)$, signet ring cell carcinoma (8490/3) and other uncommon pathological classification. Patients were excluded if they had multiple primary malignant neoplasms, incomplete TNM staging, with distant metastasis (M1), no evaluation on LNs, died within 30 days after surgery or information on CSS and survival months unavailable.

Age, sex, year of diagnosis, race, grade, $T$ stage, total number of LN examined, number of positive LNs and survival time was assessed. TNM classification was restaged according to the criteria described in the AJCC Cancer Staging Manual (7th edition, 2010).

\section{Statistical analysis}

The NLNs cutoff points were determined using the X-tile program, which identified the cutoff with the minimum $\mathrm{P}$ values from log-rank $\chi^{2}$ statistics for the categorical NLNs in terms of survival. Association of ypN stage with clinicopathological parameters was analyzed by chi-square $(\chi 2)$ test. Survival curves were generated using Kaplan-Meier estimates, and the differences were analyzed by log-rank test. Cox regression models were built for analysis of risk factors for survival outcomes. Nomogram on CSS was established according to all significant factors. Statistical analyses were performed using the statistical software package SPSS for Windows, version 19.0 (SPSS Inc, Chicago, IL, USA). Results were considered statistically significant when a two-sided $p$ values of less than 0.05 .

\section{Authors' contributions}

$\mathrm{ZQH}$ and JY conceived and designed the study, XXL, WGZ, XWZ, HLW and HSY performed the analyses, XXL, HLW, XWL and KX provided assistance in writing the manuscript and support in interpreting results. All authors discussed the results and implications of the analysis and commented on the manuscript at all stages.

\section{ACKNOWLEDGMENTS}

This work was supported by grant from National Youth Science Foundation (81402002).

\section{CONFLICTS OF INTEREST}

The authors declare that they have no competing interests.

\section{REFERENCES}

1. Torre LA, Bray F, Siegel RL, Ferlay J, Lortet-Tieulent J, Jemal A. Global cancer statistics, 2012. CA Cancer J Clin. 2015; 65:87-108.

2. Li F, Zhang R, Liang H, Liu H, Quan J, Zhao J. The pattern of lymph node metastasis and the suitability of 7th UICC $\mathrm{N}$ stage in predicting prognosis of remnant gastric cancer. $\mathrm{J}$ Cancer Res Clin Oncol. 2012; 138:111-117.

3. Shridhar R, Dombi GW, Finkelstein SE, Meredith KL, Hoffe SE. Improved survival in patients with lymph nodepositive gastric cancer who received preoperative radiation: an analysis of the Surveillance, Epidemiology, and End Results database. Cancer. 2011; 117:3908-3916.

4. Skoropad V, Berdov B, Zagrebin V. Concentrated preoperative radiotherapy for resectable gastric cancer: 20-years follow-up of a randomized trial. J Surg Oncol. 2002; 80:72-78.

5. Fiorica F, Cartei F, Enea M, Licata A, Cabibbo G, Carau B, Liboni A, Ursino S, Cammà C. The impact of radiotherapy on survival in resectable gastric carcinoma: a meta-analysis of literature data. Cancer Treat Rev. 2007; 33:729-740.

6. Zhou R, Wu Z, Zhang J, Wang H, Su Y, Huang N, Shi M, Bin J, Liao Y, Liao W. Clinical significance of accurate identification of lymph node status in distant metastatic gastric cancer. Oncotarget. 2016; 7:1029-1041. doi: 10.18632/oncotarget.6009.

7. Jian-Hui C, Shi-Rong C, Hui W, Si-le C, Jian-Bo X, Er-Tao Z, Chuang-Qi C, Yu-Long H. Prognostic value of three different lymph node staging systems in the survival of patients with gastric cancer following D2 lymphadenectomy. Tumour Biol. 2016; 37:11105-11113.

8. Chen Y, Zhang L, Tian J, Ren X, Hao Q. Combining the negative lymph nodes count with the ratio of positive and removed lymph nodes can better predict the postoperative survival in cervical cancer patients. Cancer Cell Int. 2013; 13:6.

9. He J, Wang H, Ma F, Feng F, Lin C, Qian H. Prognosis of lymph node-negative breast cancer: association with 
clinicopathological factors and tumor associated gene expression. Oncol Lett. 2014; 8:1717-1724.

10. Hsu PK, Huang CS, Wang BY, Wu YC, Chou TY, Hsu WH. The prognostic value of the number of negative lymph nodes in esophageal cancer patients after transthoracic resection. Ann Thorac Surg. 2013; 96:995-1001.

11. Shi RL, Chen Q, Ding JB, Yang Z, Pan G, Jiang D, Liu W. Increased number of negative lymph nodes is associated with improved survival outcome in node positive gastric cancer following radical gastrectomy. Oncotarget. 2016; 7:35084-35091. doi: 10.18632/oncotarget.9041.

12. Li Q, Liang L, Gan L, Cai G, Li X, Cai S. Effect of lymph node count on pathological stage III rectal cancer with preoperative radiotherapy. Sci Rep. 2015; 5:16990.

13. Bertuccio P, Chatenoud L, Levi F, Praud D, Ferlay J, Negri E, Malvezzi M, La Vecchia C. Recent patterns in gastric cancer: a global overview. Int J Cancer. 2009; 125:666-673.

14. Deng JY, Liang H. Clinical significance of lymph node metastasis in gastric cancer. World J Gastroenterol. 2014; 20:3967-3975.

15. Zuo CH, Xie H, Liu J, Qiu XX, Lin JG, Hua X, Qin A. Characterization of lymph node metastasis and its clinical significance in the surgical treatment of gastric cancer. Mol Clin Oncol. 2014; 2:821-826.

16. Deng J, Liang H, Wang D, Sun D, Ding X, Pan Y, Liu X. Enhancement the prediction of postoperative survival in gastric cancer by combining the negative lymph node count with ratio between positive and examined lymph nodes. Ann Surg Oncol. 2010; 17:1043-1051.

17. Zeng YJ, Zhang CD, Dai DQ. Impact of lymph node micrometastasis on gastric carcinoma prognosis: a metaanalysis. World J Gastroenterol. 2015; 21:1628-1635.

18. Hayashi N, Ito I, Yanagisawa A, Kato Y, Nakamori S, Imaoka S, Watanabe H, Ogawa M, Nakamura Y. Genetic diagnosis of lymph-node metastasis in colorectal cancer. Lancet. 1995; 345:1257-1259.

19. Kinoshita O, Ichikawa D, Ichijo Y, Komatsu S, Okamoto K, Kishimoto M, Yanagisawa A, Otsuji E. Histological evaluation for chemotherapeutic responses of metastatic lymph nodes in gastric cancer. World J Gastroenterol. 2015; 21:13500-13506.

20. Dong S, Yu JR, Zhang Q, Liu XS. Neoadjuvant chemotherapy in controlling lymph node metastasis for locally advanced gastric cancer in a Chinese population. $\mathrm{J}$ Chemother. 2016; 28:59-64. 